\title{
The Role of Galanin during Bacterial Infection in Larval Zebrafish
}

\author{
Natalia Nowik 1,2, Tomasz K. Prajsnar 2,3 , Anna Przyborowska 1,4 ${ }^{1,}$ Krzysztof Rakus ${ }^{3}$ D, Waldemar Sienkiewicz ${ }^{1}$, \\ Herman P. Spaink ${ }^{2}$ and Piotr Podlasz $4, * \mathbb{D}$
}

1 Department of Animal Anatomy, Faculty of Veterinary Medicine, University of Warmia and Mazury, 10-719 Olsztyn, Poland; natalia.nowik@outlook.com (N.N.); anna.jakimiuk@uwm.edu.pl (A.P.); sienio@uwm.edu.pl (W.S.)

2 Department of Animal Sciences and Health, Institute of Biology (IBL), Leiden University, 2333 BE Leiden, The Netherlands; tomasz.prajsnar@uj.edu.pl (T.K.P.); h.p.spaink@biology.leidenuniv.nl (H.P.S.)

3 Department of Evolutionary Immunology, Institute of Zoology and Biomedical Research, Faculty of Biology, Jagiellonian University, 30-387 Krakow, Poland; krzysztof.rakus@uj.edu.pl

4 Department of Pathophysiology, Forensic Veterinary and Administration, Faculty of Veterinary Medicine, University of Warmia and Mazury, 10-719 Olsztyn, Poland

* Correspondence: piotr.podlasz@uwm.edu.pl; Tel.: +48-89-5245291

Citation: Nowik, N.; Prajsnar, T.K.; Przyborowska, A.; Rakus, K.; Sienkiewicz, W.; Spaink, H.P.; Podlasz, P. The Role of Galanin during Bacterial Infection in Larval Zebrafish. Cells 2021, 10, 2011. https://doi.org/10.3390/cells10082011

Academic Editor: Edor Kabashi

Received: 1 July 2021

Accepted: 3 August 2021

Published: 6 August 2021

Publisher's Note: MDPI stays neutral with regard to jurisdictional claims in published maps and institutional affiliations.

Copyright: (c) 2021 by the authors. Licensee MDPI, Basel, Switzerland. This article is an open access article distributed under the terms and conditions of the Creative Commons Attribution (CC BY) license (https:/ / creativecommons.org/licenses/by/ $4.0 /)$.

\begin{abstract}
Galanin is a peptide that is conserved among different species and plays various roles in an organism, although its entire role is not completely understood. For many years, galanin has been linked mainly with the neurotransmission in the nervous system; however, recent reports underline its role in immunity. Zebrafish (Danio rerio) is an intensively developing animal model to study infectious diseases. In this study, we used larval zebrafish to determine the role of galanin in bacterial infection. We showed that knockout of galanin in zebrafish leads to a higher bacterial burden and mortality during Mycobacterium marinum and Staphylococcus aureus infection, whereas administration of a galanin analogue, NAX 5055, improves the ability of fish to control the infection caused by both pathogens. Moreover, the transcriptomics data revealed that a lower number of genes were regulated in response to mycobacterial infection in gal-/- mutants compared with their gal+/+ wild-type counterparts. We also found that galanin deficiency led to significant changes in immune-related pathways, mostly connected with cytokine and chemokine functions. The results show that galanin acts not only as a neurotransmitter but is also involved in immune response to bacterial infections, demonstrating the complexity of the neuroendocrine system and its possible connection with immunity.
\end{abstract}

Keywords: zebrafish; immunity; bacterial infection

\section{Introduction}

Although the connection between neuroendocrine and immune system was a doubtful matter for many years, it has recently been proved that these both systems cooperate and are complementary to each other [1,2]. This link is regulated by a number of neuropeptides, which play different roles in innate immunity, while in turn, immune cells regulate the neural function by cytokines [3-6].

Galanin has been already known for almost forty years [7]; however, its entire role remains unrevealed. The galanin family includes galanin, the galanin-like peptide (GALP), the galanin-message associated peptide (GMAP) and alarin. Galanin is present mainly in the central nervous system as well as in the peripheral tissues of many different species [8-11]. It is also involved in many biological processes such as regulation of the circadian rhythm, brain development, pain, food intake, stress, metabolism and inflammation [12]. Moreover, it has been shown to participate in inflammatory diseases such as inflammatory bowel disease and ulcerative colitis [13,14], skin inflammation [15] or even 
infectious diseases such as tuberculosis [16]. Galanin acts through its receptors (GALRs) that belong to the G-protein-couple receptor (GPCR) superfamily, which in mammals consists of three subfamilies, namely GalR1, GalR2 and GalR3 [17]. In the zebrafish, no GalR3 gene is present, but GalR1 and GalR2 genes are duplicated, which means there are four galanin receptor genes in zebrafish: GalR1a, GalR1b, GalR2a and GalR2b [18]. The expression of galanin receptors is very common in many tissues of adult zebrafish and appears very early in development, even as a maternal transcript (XX) [19-21].

Their structure is composed of three intercellular loops (ICLs), an extracellular Nterminus, three intracellular loops, and three extracellular loops (ECLs). The helix eight at the C-termini, which is located parallel to the membrane, is present in all models [17].

Because of its genetic and physiological similarities to mammals, zebrafish (Danio rerio) is an extremely useful animal model to study various non-infectious and inflammatory diseases. The embryos are transparent, they develop ex utero and are susceptible to genetic manipulations, such as gene knockout [22]. Its genome has been fully sequenced and shows $70 \%$ similarity with the human counterpart [23]. Zebrafish have been extensively used for studying cancer, inflammatory diseases and non-infectious diseases [24-26]. Galanin gene is highly conserved in different species, including the zebrafish [11]. The structure of zebrafish galanin gene is identical with the gene present in mammals: It comprises six exons and contains a signal peptide, galanin and GMAP domains. The mature peptide contains 29 amino acids, and the N-terminal amino acids 1-13 (GWTLNSAGYLLGP) are identical in all species including zebrafish from which galanin has been identified, except in tuna where the serine in position 6 has been substituted with an alanine [27]. This strong evolutionary conservation may suggest important and similar roles of galanin in all vertebrates.

Mycobacterium tuberculosis ( $\mathrm{Mtb}$ ) is a pathogen that is responsible for the leading deadly infectious disease of humans, of which the cell wall resembles both the Gram-positive and Gram-negative characteristics. This bacterium is estimated to have infected one-third of the world population and to be responsible for nine million new cases of tuberculosis (TB) [28]. The main feature of TB is the development of granulomas that consist of infected macrophages and necrotic cell debris, which form at the site of infection [29]. Granulomas are a hallmark of latent infection that can persist for many years without clinical signs and can be reactivated into the systemic infection again. In turn, Staphylococcus aureus is a Gram-positive opportunistic pathogen able to cause infection in multiple tissues of the host. The range of pathologies varies from local cutaneous lesions to more serious infections such as osteomyelitis and life-threatening sepsis [30,31]. Methicillin, or more often, vancomycin-resistant strains, cause difficulties in treatment and become a huge threat to public health worldwide [32].

Many animal models including zebrafish have been used for mycobacterial and staphylococcal research to identify their molecular background as well as the development of new drugs and current treatment support [33]. Zebrafish have been exploited as a model for TB for almost 20 years since it is a natural host for one of the mycobacterial strains, Mycobacterium marinum, which shares $85 \%$ of its amino acid identity with the human Mtb [34]. In the zebrafish model, M. marinum causes a similar systematic disease with the formation of granulomas and the response of the innate immune system, which is completely functional at $28 \mathrm{hpf}$ (hours post fertilization) [35], without the interference of the adaptive immune system, which is developed after 4-6 weeks post fertilization [36]. This implicates the role of the innate immune system in the development of TB and helps to underline its role in the TB pathogenesis [37]. In contrast, zebrafish is not a natural host of $S$. aureus, although a staphylococcal infection model has been successfully established in zebrafish larvae [38].

NAX 5055 (Gal-B2) is a galanin analogue that was chosen for this study due to its bioavailability, metabolic stability, selectivity for galanin receptors and ability to penetrate the blood-brain barrier (BBB) [39]. Other galanin agonists such as galmic and galnon show 
little receptor subtype specificity, lower affinity for galanin receptors relative to the native peptide and many off-target effects [39,40].

Galanin is conserved among mammals and lower vertebrates, although its role during an infection has not been precisely determined. In this study, we took a genetic and chemical approach to study the role of galanin in the immune response to bacterial infections in the zebrafish larvae. Our results showed that bacterial infection in the absence of endogenous galanin resulted in increased mortalities and bacterial burden, whereas treatment with galanin analog NAX 5055 rescued the hypersusceptibility of the galanin-deficient larvae.

\section{Materials and Methods}

\subsection{Fish Maintenance}

CRISPR-Cas9 technology was used to generate a galanin mutant (gal-/-) as described [41]. The mutant has a 10-base-pair deletion in the 3rd exon of the gal gene (Ensembl (GRCz11): ENSDARG00000091377), which results in a loss-of-function allele due to a frameshift and premature stop codon. A detailed description of this mutant is in preparation for a separate publication (unpublished data).

The wild-type gal+/+ and $g a l-/-$ mutant larvae were maintained as described previously [42]. Embryos were raised in E3 medium ( $5 \mathrm{mM} \mathrm{NaCl} .0 .17 \mathrm{mM} \mathrm{KCl} .0 .33 \mathrm{mM} \mathrm{CaCl}_{2}$. $0.33 \mathrm{mM} \mathrm{MgSO}_{4}$ ) at $28.5^{\circ} \mathrm{C}$. During imaging, fish were kept under anesthesia in egg water containing $0.02 \%$ buffered 3-aminobenzoic acid ethyl ester (Tricaine, Sigma-Aldrich, St. Louis, MO, USA).

All fish lines are housed both in the fish facility of the Laboratory of Genomics and Transcriptomics, University of Warmia and Mazury in Olsztyn, Poland, which was built according to the local animal welfare standards and in the fish facility of Leiden University compliant with the directives of the local animal welfare committee. Studies performed on early-life-stage zebrafish larvae and euthanasia do not require Ethic Committee permissions. According to the European Directive 2010/63/EU and Polish law regulations O.J. of 2015, item 266.

\subsection{Bacteria Preparation}

Mycobacterium marinum strain 20, labelled with mCherry [43], was grown on Difco Middlebrook 7H10 agar (BD and company) supplemented with 10\% oleic acid-albumindextrose-catalase (OADC, BD and company), $0.5 \%$ glycerol and with hygromycin to select for fluorescence expression vectors. A colony of M. marinum was resuspended in Difco Middlebrook 7H9 broth (BD and company) supplemented with 10\% albumin-dextrose-catalase (ADC, BD and company), 0.05\% Tween 80 (Sigma-Aldrich) and $50 \mu \mathrm{g} / \mathrm{mL}$ hygromycin. Bacterial cultures grown overnight at $28.5^{\circ} \mathrm{C}$ were washed in PBS, spun down and resuspended to the desired concentration (to obtain $40 \mathrm{CFU}$ for yolk injections and $120 \mathrm{CFU}$ for caudal vein injections) in $2 \%$ polyvinylpyrrolidone (PVP40, CalBiochem) in PBS. Phenol red (Sigma-Aldrich) was added to a concentration of $0.085 \%$ to visualize the injection process [43].

The Staphylococcus aureus SH1000 strain, carrying the pMV158-mCherry plasmid [44], was grown in a brain heart infusion (BHI) broth medium (Oxoid, Basingstoke, UK) supplemented with tetracycline $5 \mu \mathrm{g} \mathrm{mL} \mathrm{L}^{-1}$ at $37^{\circ} \mathrm{C}$. Bacteria were cultured until OD600 (optical density at $600 \mathrm{~nm})$ reached approximately 1 . After centrifugation $(4500 \times g, 10$ min), the supernatant was discarded, and the pellet was re-suspended in sterile PBS to the desired concentration (to obtain $20 \mathrm{CFU}$ for yolk injections and $1200 \mathrm{CFU}$ for caudal vein injections [38].

\subsection{Infection}

For yolk infection, embryos were collected immediately after single crossing and infected into the yolk between 4-6 hpf. For caudal vein infection, embryos were dechorionated manually at $24 \mathrm{hpf}$, anaesthetized and injected individually into the caudal vein 
using glass microcapillary pipettes with $1 \mathrm{~nL}$ of bacterial suspension at 28-30 hpf. The same volume of PBS was injected into the mock control $[38,43]$.

\subsection{Treatment with NAX 5055}

The zebrafish embryos were injected twice with galanin analogue NAX 5055 (a kind gift from Drs. Steve White and Grzegorz Bulaj from the University of Utah [39]). The group infected into the yolk received only one dose of NAX 5055, while those infected into the caudal vein were administered twice. The first injection with $1 \mathrm{~nL}$ of NAX 5055 in a concentration of $5 \mu \mathrm{g} / \mathrm{g}$ was performed at the first hour postfertilization into the yolk of the embryos, whereas the second injection of the same concentration was performed together with the bacterial delivery into the caudal vein. During the incubation period, the gal-/- larvae were kept in the egg water containing $20 \mu \mathrm{M}$ of NAX 5055 at $28^{\circ} \mathrm{C}$. The gal+/+ infected larvae and the mock control fish injected with PBS were kept under the same conditions in the egg water as the treated group.

\subsection{Imaging and Fluorescence Quantification}

A Leica fluorescence (MZ16 FA) stereo microscope was used to take images of zebrafish larvae. During imaging, embryos were kept under anesthesia (0.02\% Tricaine, (Sigma) in E3). To quantify fluorescence of bacterial burden in individual embryos, the fluorescent images of embryos with custom-made, dedicated pixel quantification software were performed [45].

\subsection{RNA Isolation and RT-qPCR}

RNA was isolated using in QIAzol lysis reagent (Qiagen, Hilden, Germany) for RNA isolation, which was performed using the miRNeasy mini kit (Qiagen), according to the manufacturer's instructions. Two hundred nanograms of isolated RNA was reverse transcribed using the iScript cDNA Synthesis Kit (Bio-Rad Laboratories B.V., Hercules, CA, USA) according to the manufacturers' protocols. For the quantification of mRNA expression, qPCR was carried out using iQ SYBR Green Supermix (Bio-Rad Laboratories B.V.). RT-qPCR was performed on a MyiQ Single-Color Real-Time PCR Detection System (Bio-Rad). Cycling conditions were pre-denaturation for $3 \mathrm{~min}$ at $95^{\circ} \mathrm{C}$, followed by 40 cycles of denaturation for $15 \mathrm{~s}$ at $95^{\circ} \mathrm{C}$, annealing for $30 \mathrm{~s}$ at $60^{\circ} \mathrm{C}$ and elongation for $30 \mathrm{~s}$ at $72{ }^{\circ} \mathrm{C}$. $\left(0.5^{\circ} \mathrm{C}\right.$ increments for every $\left.10 \mathrm{~s}\right)$. For every sample, the $\mathrm{Ct}$ value was determined from the $\mathrm{Ct}$ value of a non-infected control sample, and the fold change of gene expression was calculated and normalized to the expression levels of a reference gene: peptidylprolyl isomerase Ab (ppiab), since its expression did not change significantly after M. marinum infection in the infected larvae [46]. Results were analyzed using the $\Delta \Delta C t$ method [47]. Data shown are mean \pm s.e.m. of three independent experiments. The primer sequences are described in the Supplementary Table S1.

\subsection{RNA-Seq Analysis}

Zebrafish embryos ( $\mathrm{gal}+/+$ and $g a l-/-$ ) were either infected intravenously at $28 \mathrm{hpf}$ with M. marinum or mock-infected with PBS and were divided into four experimental groups: (i) gal+/+ uninfected, (ii) gal+/+ infected, (iii) gal-/- uninfected and (iv) gal-/infected. At 4 days post infection (dpi) 15 embryos per group were collected, snap-frozen in liquid nitrogen and stored at $-80^{\circ} \mathrm{C}$. Total RNA was extracted according to the manufacturer's instructions, using TRIzol (Life Technologies, Carlsbad, CA, USA). A total of $2 \mu \mathrm{g}$ of RNA was used to make RNAseq libraries using the Illumina TruSeq RNA Sample Preparation Kit v2 (Illumina, Inc., San Diego, CA, USA). The resulting mRNAseq library was sequenced using an Illumina HiSeq2500 Instrument (Illumina, Inc.) according to the manufacturer's instructions with a read length of $2 \times 50$ nucleotides. Data analysis was performed using Genetiles Software (www.genetiles.com, accessed on 30 December 2015, described in [48]), whereas gene ontology and pathways analysis were performed using DAVID Functional Annotation Tool (https:/ / david.ncifcrf.gov/, accessed 
on 15 May 2016). Paired analysis was performed using DESeq2 comparing each group ( $\mathrm{gal}+/+$ infected vs./gal-/- infected) to the respective control group ( $\mathrm{g} a \mathrm{l}+/+$ non-infected vs./gal-/- non-infected). Significantly regulated genes were selected by using $p<0.05$ and | FoldChange | $>1.5$ cutoff.

\subsection{COPAS Analysis}

We used COPAS ${ }^{\mathrm{TM}}$ XL (Complex Object Parametric Analyzer and Sorter, Union Biometrica, Holliston, MA, USA) to monitor the development of the infection, fluorescence and spreading of the infection. The COPAS ${ }^{\mathrm{TM}} \mathrm{XL}$ large particle sorter has been designed for the analysis, sorting and dispensing of objects up to $1.5 \mathrm{~mm}$ in diameter based on size, optical density and fluorescence intensity. The $561 \mathrm{~nm}$ Solid State laser was used for mCherry detection. Zebrafish embryos were measured alive at indicated time points, to determine their bacterial burden with the COPAS XL using the following settings: Photo multiplier tube voltage: $650 \mathrm{~V}$ for red and $0 \mathrm{~V}$ for yellow, optical density threshold signal $975 \mathrm{mV}$ (COPAS value: 50) and time of flight minimum $320 \mu$ s (COPAS value: 800) [48].

\subsection{Statistical Analysis}

Statistical analysis was performed using GraphPad Prism 8 (GraphPad Software, La Jolla, CA, USA). Survival experiments were evaluated using the Kaplan-Meier method. Comparisons between curves were made using the log rank test. Differences in bacterial burden were statistically tested by one-way ANOVA followed by Tukey's comparison test (multiple group comparisons). For RT-qPCR, statistical significance was estimated by two-tailed $t$-tests on $\ln (\mathrm{n})$-transformed relative induction folds. Significance ( $p$-value) is indicated with ns, non-significant; ${ }^{*} p<0.05 ;{ }^{* *} p<0.01{ }^{* * *} p<0.001,{ }^{* * *} p<0.0001$. Error bars are the mean \pm s.e.m.

\section{Results}

\subsection{Bacterial Infection in Galanin-Deficient Zebrafish Larvae}

In order to investigate the role of galanin during bacterial infection, fluorescent M. marinum or S. aureus was administered into the yolk of approximately 50 zebrafish larvae at the 4-6 hpf. The infection was monitored as long as possible up to $5 \mathrm{dpi}$ for both host survival and bacterial burden, which was calculated using COPAS flow cytometry, fluorescence microscopy and a dedicated pixel count software.

Infection in the yolk progressed rapidly and caused high mortality in the case of both pathogens used. M. marinum yolk infection resulted in significantly higher mortality among the $g a l-/-$ mutants (73\%) than in the gal+/+ wild-type group (35\%) after $96 \mathrm{~h}$ post infection (hpi) (Figure 1A). S. aureus yolk infection resulted in $100 \%$ death in the gal-/group, compared to the gal+/+ wild-type infected group that reached mortality of $40 \%$ after 20 hpi (Figure 1B). The progression of M. marinum infection was determined using the dedicated pixel quantification software after 5 dpi with the bacterial burden being approximately 1.5 times higher in the galanin-deficient group ( $\mathrm{gal}-/-$ ) compared to the wild-type embryos ( $\mathrm{gal}+/+$ ) (Figure 1C). The burden of S. aureus infection was measured with the same method after 15 hpi and was three times higher among the mutants $(\mathrm{gal}-/-)$ than the wild-type larvae ( $g a l+/+)$ (Figure 1D). 
A

M. marinum infection

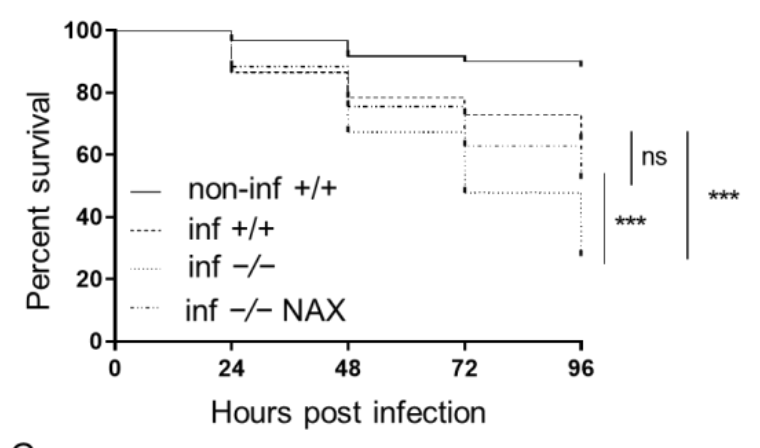

C

M. marinum infection

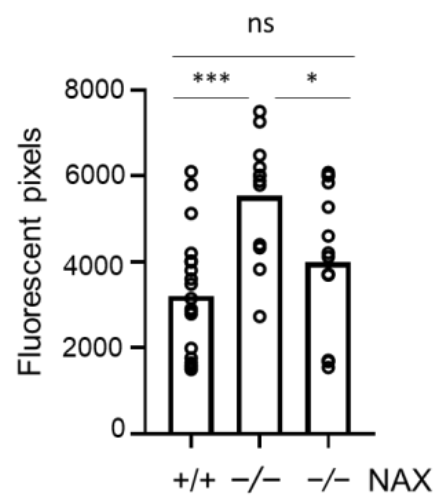

B

S. aureus infection

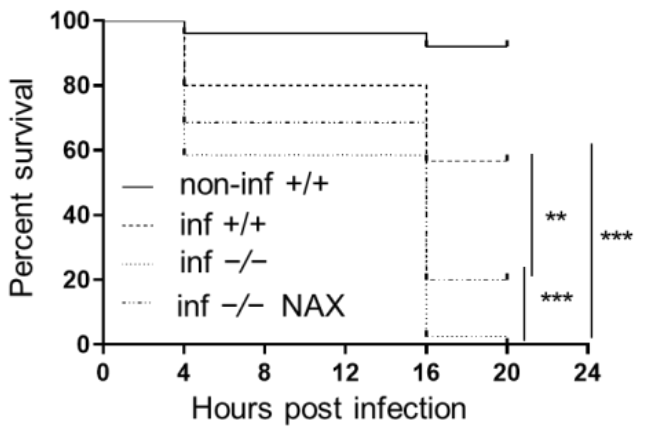

S. aureus infection

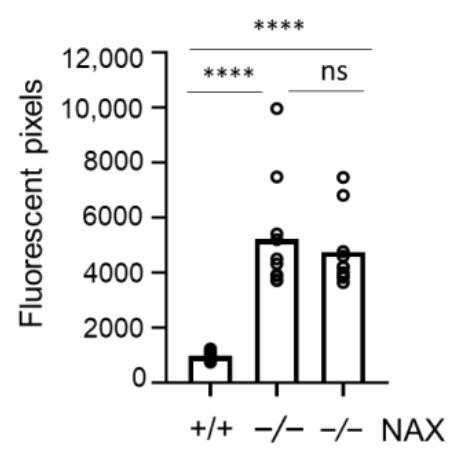

Figure 1. Galanin deficiency results in higher mortality and bacterial burden after yolk infection. (A,B) Survival rate in mock-injected larvae (non-inf +/+), infected wild-types (inf +/+), infected gal-/- mutants (inf -/-) and infected gal-/mutants treated with NAX 5055 (inf -/- NAX) after (A) M. marinum or (B) S. aureus yolk infection. (C,D) Bacterial burden in infected wild-type larvae, infected gal-/- mutants and infected gal-/- mutants treated with NAX 5055 after (C) M. marinum or (D) S. aureus yolk infection. Data are combined from three biological replicates ( $\mathrm{n}=10$ larvae/group). ${ }^{*} p<0.05$; ${ }^{* *} p<0.01 ;{ }^{* * *} p<0.001 ;{ }^{* * *} p<0.0001$; ns, non-significant.

Subsequently, we employed the model of systemic infection. Compared with the yolk infection model, zebrafish embryos were more resistant to the infection induced by intravenous infection, which has been observed before [32]. The injections were performed after 28-30 hpf in approximately 30 larvae, followed until $5 \mathrm{dpf}$ (4 dpi) and measured using the same pixel counting software and COPAS flow cytometry. When injected into the circulation, the gal-/- mutant infected with M. marinum were more vulnerable to the infection than the control group, reaching mortality of $50 \%$ compared to $17 \%$ in the gal+/+ wild-type group (Figure 2A). Furthermore, S. aureus infection into circulation showed higher mortality in the gal-/- mutants reaching $82 \%$, compared to $48 \%$ in the infected gal+/+ wild-type siblings (Figure 2B). After $4 \mathrm{dpi}$, the M. marinum infection burden was significantly higher in the gal-/- mutant larvae than the gal+/+ wild-type siblings (Figure 2C). Similarly, S. aureus bacterial burden was two times higher in the gal-/- group compared to the gal+/+ wild-type larvae (Figure 2D).

Taken together, the obtained data show that galanin deficiency led to increased host mortality and a higher bacterial burden during bacterial infection suggesting a protective effect of galanin in immunity to bacterial pathogens. 
A

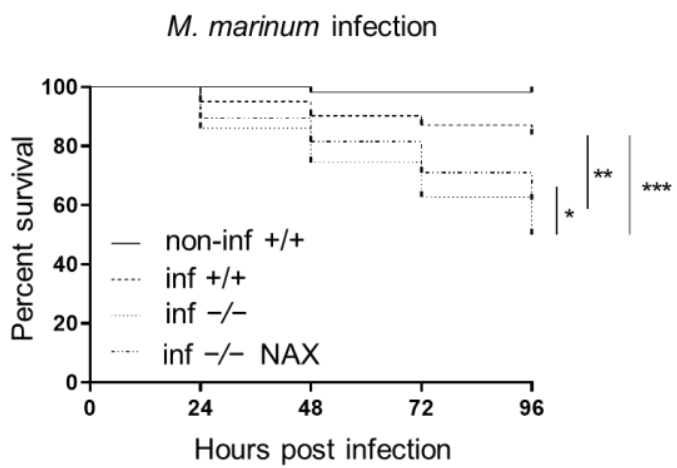

C

M. marinum infection

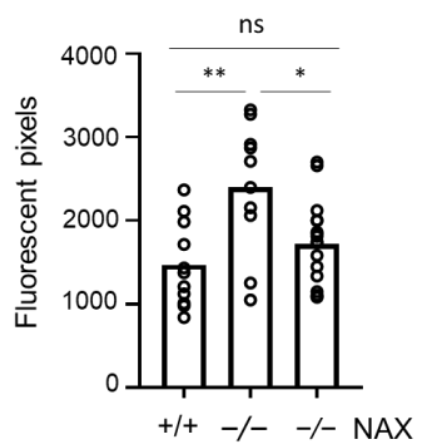

B

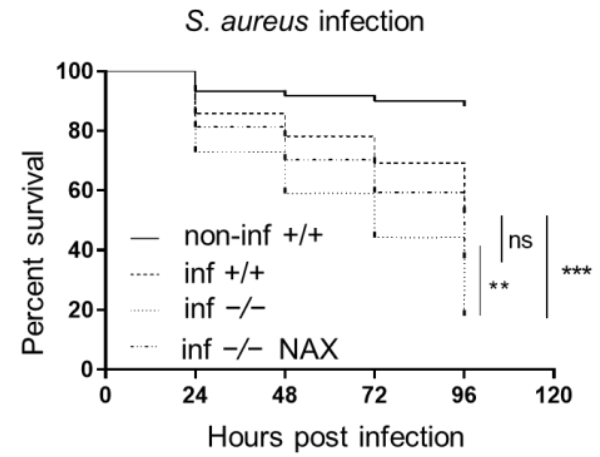

D

S. aureus infection

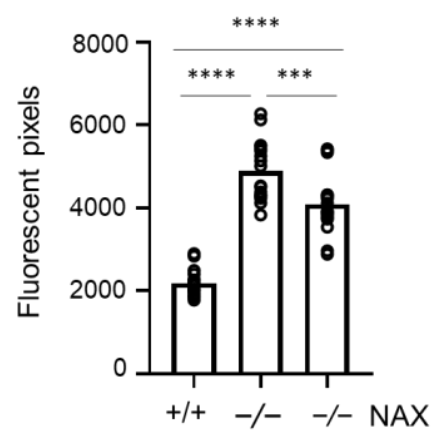

Figure 2. Galanin deficiency results in higher mortality and bacterial burden after vein infection. (A,B) Survival rate in mock injected larvae (non-inf +/+), infected wild-types (inf +/+), infected gal-/- mutants (inf -/-) and infected gal-/mutants treated with NAX 5055 (inf -/- NAX) after (A) M. marinum or (B) S. aureus vein infection. (C,D) Bacterial burden in infected wild-type larvae, infected gal-/- mutants and infected gal-/- mutants treated with NAX 5055 after (C) M. marinum or (D) S. aureus vein infection. Data are combined from three biological replicates ( $\mathrm{n}=10$ larvae/group). ${ }^{*} p<0.05$; ${ }^{* *} p<0.01 ;{ }^{* * *} p<0.001 ;{ }^{* * *} p<0.0001 ;$ ns, non-significant.

\subsection{NAX 5055 Treatment in the Infected Galanin Mutants}

In order to test how the exogenous galanin analog NAX 5055 influences progression of disease in the mutant zebrafish, the gal-/- larvae mutant larvae were injected with NAX 5055 and infected. Yolk infection with M. marinum resulted in significantly lower mortality that reached $48 \%$ in the gal-/- treated mutants group compared to the untreated gal-/- mutants (73\%) (Figure 1A). NAX 5055 treatment also led to slower progression of S. aureus infection in the gal-/- mutants with $80 \%$ mortality after 20 hpi (Figure 1B) while $100 \%$ mortality was observed in the gal-/- non-treated group. Yolk M. marinum infection resulted in a significantly lower bacterial burden in the gal-/- NAX 5055-treated group compared to the untreated gal-/- mutant larvae, reducing it to the level observed in the $g a l+/+$ infected group (Figure 1C). The level of S. aureus infection in gal-/- mutant larvae after NAX 5055 treatment was not significantly changed when compared to the gal-/untreated mutant group (Figure 1D).

Treatment with NAX 5055 resulted in an improvement in the survival of gal-/mutants infected systematically with $M$. marinum, where the level of mortality reached $38 \%$ (Figure 2A). NAX 5055 administration was able to reduce the mortality of infected $S$. aureus gal-/- mutants that reached $65 \%$ (Figure $2 \mathrm{~B}$ ). The infection burden upon caudal vein infection with $M$. marinum in the gal -/- mutant was significantly reduced after NAX 5055 treatment (Figure 2C), to the level observed in gal+/+ wild-type counterparts. Next, we found that with $S$. aureus, the infection burden was significantly lowered after NAX 5055 treatment compared to the untreated mutant group; however, it did not reach the level of the wild-type siblings (Figure 2D). In addition, we tested the effect of NAX 5055 in 
wild-type embryos (Figure S1) and found that galanin analogue supplementation leads to a lower bacterial burden of $M$. marinum compared to untreated embryos. Collectively, the results show that treatment with the galanin analogue NAX 5055 is able to improve survival and reduce bacterial burden of infected $g a l-/-$ individuals and further suggests the host-protective role of galanin in bacterial infection.

\subsection{Galanin Deficiency and Immune-Related Gene Expression}

Having observed the host-detrimental effect of galanin knockout in bacterial infection, we decided to determine how galanin deficiency affects the expression of immune-related genes. We performed a reverse transcription-quantitative PCR (RT-qPCR) for four genes: irg1l, illb, tnfa and cxcl8a (il8) in infected gal+/+, gal-/- and gal-/- larvae treated with NAX 5055. In the gal-/- group, the expression of irg1l was downregulated when compared to the $g a l+/+$ zebrafish larvae infected with M. marinum (Figure 3A). Moreover, in the same group, the expression of pro-inflammatory cytokines $i l 1 b$, tnfa and cxcl8a was also downregulated, in comparison to the wild-type gal+/+ infected zebrafish larvae (Figure 3A). On the other hand, treatment with NAX 5055 lowered the expression of irgl1l, as well as $i l 1 b$, tnfa and cxcl8a in the gal-/- larvae (Figure 3A). We also performed the same analysis to determine the levels of abovementioned genes after $S$. aureus infection. The expression of irglll was significantly downregulated in the gal-/- mutant after staphylococcal infection, whereas treatment with NAX 5055 augmented its mRNA level (Figure 3B). The expression levels of $i l 1 b$ and $c x c l 8 a$ were also significantly lower in the gal-/- mutant, although we did not notice its significant upregulation after the treatment with NAX 5055 (Figure 3B). The tnfa expression was slightly lower after the knockout; however, it was not statistically significant compared to gal+/+ wild-types (Figure 3B).

A

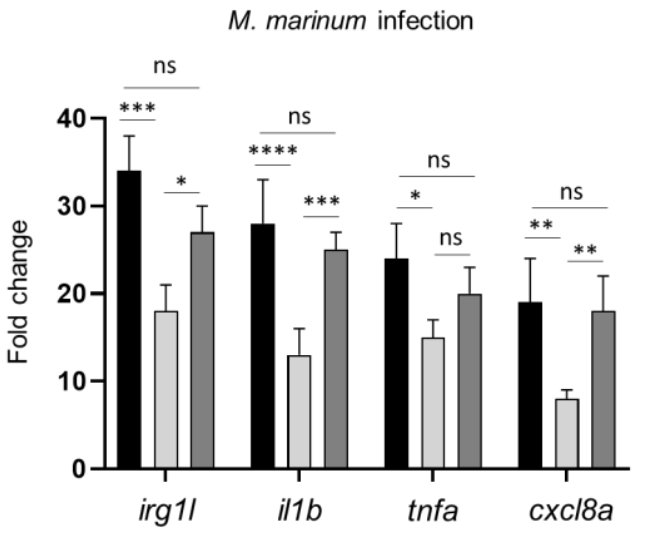

B

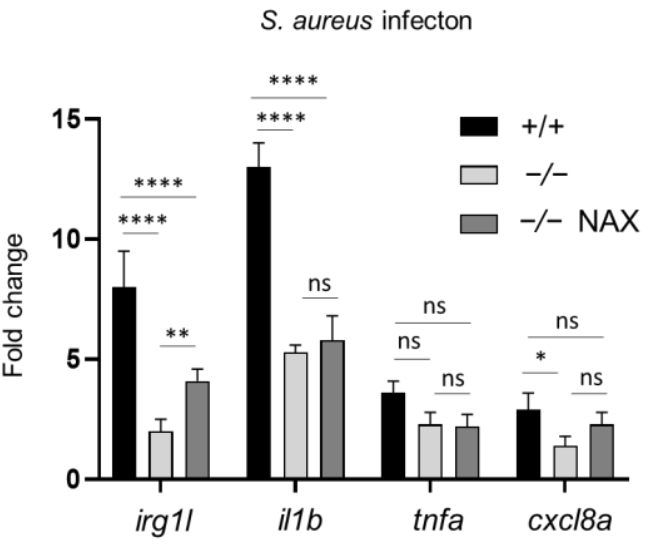

Figure 3. Expression levels of immune-related genes determined by RT-qPCR. irg $11, i l 1 b$, $t n f a$ and $c x c l 8 a$ levels after (A) M. marinum or (B) S. aureus infection. Data are mean \pm s.e.m. of three independent experiments. ${ }^{*} p<0.05$; ${ }^{* *} p<0.01$; $* * * p 0.001 ; * * * * 0.0001$ (determined using ANOVA with a Fisher's LSD post hoc). ns, non-significant.

Collectively, these results suggest that galanin modulates the production of proinflammatory cytokines and therefore could be involved in immune processes during mycobacterial and staphylococcal infection.

\subsection{Transcriptomic Profiling of Galanin-Deficient Zebrafish Larvae Infected with M. marinum}

Knowing that galanin plays a host-protective role during mycobacterial infection in larval zebrafish and is involved in the regulation of the tested immune-related genes, we wanted to determine the differences in in gene regulation between gal+/+ wild-type larvae and knockout gal-/- mutants in response to $M$. marinum infection. We analyzed the transcriptomes of control vs. infected larvae in gal+/+ (Table S3) and gal-/- larvae (Table S4) using the whole zebrafish larvae at $4 \mathrm{dpi}$. In gal+/+ larvae, the infection led to the upregulation of 1578 genes, whereas only 812 genes were upregulated in the gal-/- 
larvae (Figure 4A) revealing that the loss of galanin has a dampening effect on the infectioninduced changes in gene expression. In terms of the downregulated genes, the expression of 643 vs. 599 genes were negatively affected by mycobacterial infection in gal+/+ vs. gal-/- larvae, respectively. Interestingly, only 466 and 56 genes were present in the overlap between these two groups for upregulation and downregulation, respectively (Figure 4A). A comparison of changes in the expression levels and fold change between the infected gal+/+ and gal-/- mutant larvae was visualized by heat maps, which show higher upregulation in the gal+/+ wild-type group than in the gal-/- mutant group (Figure 4B) and, importantly, it reveals that many genes were expressed oppositely to each other depending on the presence of galanin (Figure 4B). To study the effect of galanin knockout on the changes in gene expression caused by mycobacterial infection, we plotted the level of gene expression changed by the infection in the gal-/- mutants against infection in the gal+/+ wild-type group for all genes that were significantly regulated by at least one of these conditions. The plot confirms that more genes are regulated in the gal+/+ group, where most of them are upregulated, whereas in gal-/- mutants, most of the genes are downregulated (Figure 4C).

A

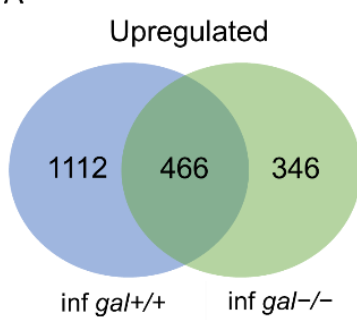

C

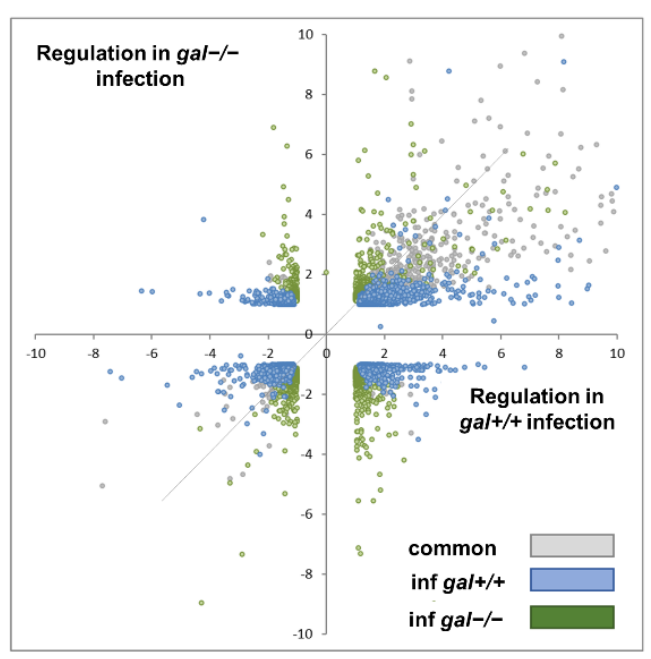

B

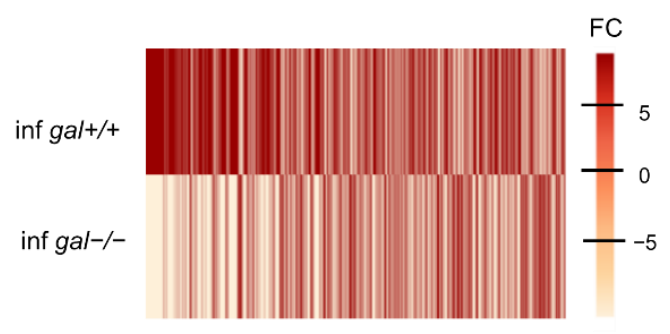

D
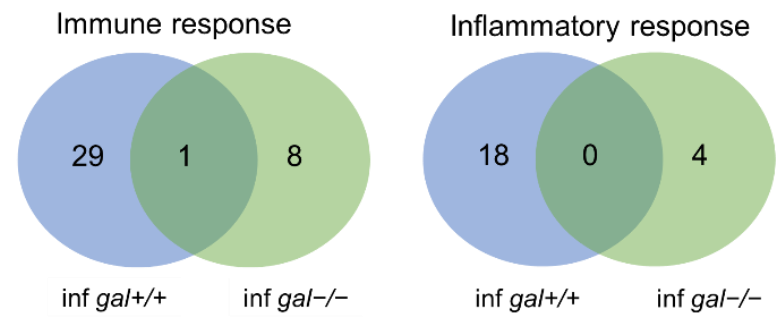

Response to bacterium

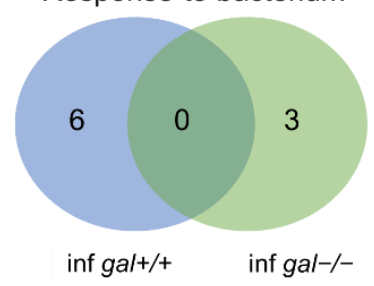

Figure 4. Transcriptome analysis by RNA-seq showing modulation of infection-induced gene regulation by galanin mutation. (A) Venn diagram showing overlaps between clusters of genes significantly upregulated or downregulated by infection of $g a l+/+$ and gal-/- mutant larvae; (B) heat map displaying the normalized fold changes of transcripts that reached statistical significance as differentially expressed in infected gal+/+ and infected gal-/- zebrafish larvae; (C) scatter plot showing the effect of galanin deficiency on gene expression. For all genes showing significant regulation upon infection (blue and gray dots) or the combined infection in the mutant (gray dots). Gray dots represent the overlap between control infection and mutant infection. The gray line indicates the point at which galanin knockout treatment does not alter infection-induced gene regulation; (D) GO analysis for upregulated genes in biological processes. Paired analysis was per-formed using DESeq2 by comparing each group to each non-infected group. Significantly regulated genes were selected by using a $p$.adj $<0.05$ and I FoldChange I $>1.5$ cutoff. 
Next, the Gene Ontology (GO) analyses of significantly regulated genes were performed in both wild-type gal+/+ and gal-/- mutant larvae, after M. marinum infection. Significantly affected KEGG pathways and GO:biological processes were determined by submission of the significantly regulated zebrafish genes to DAVID bioinformatic tools (https:/ / david.ncifcrf.gov). Based on the results, we classified and compared the regulated genes according to the significant KEGG pathways and biological processes that they are involved in. After taking a closer look into differences between infected gal+/+ and gal-/larvae, we identified three processes that were common for both groups, namely Immune response, Inflammatory response and Response to bacterium (Figure 4D and Table 1). In Immune response, 30 genes were upregulated in the $g a l+/+$, while only 9 genes were upregulated in gal-/- mutant. Moreover, there was only one common gene for both groups. In Inflammatory response and Response to bacterium, we identified no common genes for both groups. In the case of these processes, there were markedly more upregulated genes in the gal+/+ group than in the gal-/- mutant larvae (Figure 4D and Table 1). A comparison of the two groups showed that the common biological processes in the gal+/+ group contained more regulated genes than in the gal-/- mutant larvae (Table 1) (Figure 4D). We did not identify any biological processes connected to immune response among downregulated genes in both groups (Table 1). Further analysis showed that the group of KEGG pathways involved in immunity and regulated by mycobacterial infection in the gal+/+ wild-types and in the gal-/- mutants were opposite to each other (Table 1). Actually, the analysis showed that two significantly changed pathways, the Cytokine-cytokine receptor interaction and the JAK-STAT signaling pathway, were upregulated in the gal+/+ wild-type group but downregulated in the gal-/- mutants (Table 1). Significantly changed biological processes connected with immune response were upregulated in both gal+/+ and gal-/- groups; however, more terms were significantly changed in the gal+/+ group (Table 1). Among the common biological processes we identified, the only common gene was ccl19a.1 (chemokine (C-C motif) ligand 19a, tandem duplicate 1). All the other genes in the three common processes were different (Table 2). Additionally, we analyzed two pathways that were overlapping between gal+/+ and gal-/- mutants, namely the Cytokine-cytokine receptor interaction and the JAK-STAT signaling pathway (Table 2). In addition, in this case, only a few genes were shared by both groups (Figure 5A,B). In the Cytokine-cytokine receptor interaction, we identify osmr (oncostatin $M$ receptor) and csf1r (colony stimulating factor 1 receptor), whereas in the JAK-STAT signaling pathway, only osmr was common for the two groups (Figure 5A,B).

Table 1. Comparisons of affected pathways and biological processes in gal+/+ wild-type and gal-/- mutant larvae after $M$. marinum infection. Common processes are marked as grey.

\begin{tabular}{ccc}
\hline & KEGG-Pathways & \\
\hline UPREGULATED & gal-I- & TERM \\
\hline TERM & COUNT & Protein processing in endoplasmic reticulum \\
\hline Cytokine-cytokine receptor interaction & 18 & 11 \\
\hline Jak-STAT signaling pathway & 13 & 12 \\
\hline Herpes simplex infection & 11 \\
\hline Cell adhesion molecules (CAMs) & 11 \\
\hline FoxO signaling pathway & 10 \\
\hline p53 signaling pathway & 10 \\
\hline Toll-like receptor signaling pathway & 8 \\
\hline Tight junction & 8 \\
\hline Insulin resistance & \\
\hline
\end{tabular}


Table 1. Cont.

\begin{tabular}{|c|c|c|c|}
\hline \multicolumn{4}{|c|}{ KEGG-Pathways } \\
\hline \multicolumn{4}{|c|}{ UPREGULATED } \\
\hline \multicolumn{2}{|l|}{$g a l+/+$} & \multicolumn{2}{|l|}{ gal-I- } \\
\hline TERM & COUNT & TERM & COUNT \\
\hline Apoptosis & 7 & & \\
\hline Adipocytokine signaling pathway & 7 & & \\
\hline RIG-I-like receptor signaling pathway & 6 & & \\
\hline Cytosolic DNA-sensing pathway & 5 & & \\
\hline Arachidonic acid metabolism & 5 & & \\
\hline Steroid biosynthesis & 4 & & \\
\hline \multicolumn{4}{|c|}{ DOWNREGULATED } \\
\hline Cell cycle & 12 & MAPK signaling pathway & 10 \\
\hline Purine metabolism & 11 & Vascular smooth muscle contraction & 7 \\
\hline Focal adhesion & 11 & Melanogenesis & 6 \\
\hline ECM-receptor interaction & 10 & Cytokine-cytokine receptor interaction & 6 \\
\hline Melanogenesis & 8 & Jak-STAT signaling pathway & 5 \\
\hline DNA replication & 7 & Glycolysis/Gluconeogenesis & 4 \\
\hline Pyrimidine metabolism & 6 & Steroid biosynthesis & 3 \\
\hline Tyrosine metabolism & 5 & Galactose metabolism & 3 \\
\hline Phototransduction & 4 & & \\
\hline Retinol metabolism & 4 & & \\
\hline Glutathione metabolism & 4 & & \\
\hline Caffeine metabolism & 2 & & \\
\hline
\end{tabular}

GO: Biological processes

UPREGULATED

\begin{tabular}{|c|c|c|c|}
\hline \multicolumn{2}{|l|}{$g a l+/+$} & \multicolumn{2}{|l|}{ gal-l- } \\
\hline TERM & COUNT & TERM & COUNT \\
\hline Proteolysis & 46 & Immune response & 9 \\
\hline Immune response & 30 & Cell redox homeostasis & 5 \\
\hline Oxidation-reduction process & 27 & Protein folding & 4 \\
\hline Inflammatory response & 18 & Inflammatory response & 4 \\
\hline Regulation of cell proliferation & 15 & Response to endoplasmic reticulum stress & 3 \\
\hline Cell adhesion & 15 & Gene silencing by RNA & 3 \\
\hline Regulation of apoptotic process & 14 & $\begin{array}{l}\text { Polyadenylation-dependent snorna } 3^{\prime} \text {-end } \\
\text { processing }\end{array}$ & 3 \\
\hline Protein ubiquitination & 12 & CUT catabolic process & 3 \\
\hline Innate immune response & 11 & Response to bacterium & 3 \\
\hline Chemotaxis & 8 & $\begin{array}{l}\text { Nuclear polyadenylation-dependent rrna } \\
\text { catabolic process }\end{array}$ & 2 \\
\hline Response to lipopolysaccharide & 8 & $\begin{array}{c}\text { DNA methylation involved in gamete } \\
\text { generation }\end{array}$ & 2 \\
\hline Blood coagulation & 7 & Pirna metabolic process & 2 \\
\hline Cytokine-mediated signaling pathway & 7 & $\begin{array}{c}\text { Exonucleolytic nuclear-transcribed mrna } \\
\text { catabolic process involved in } \\
\text { deadenylation-dependent decay }\end{array}$ & 2 \\
\hline
\end{tabular}


Table 1. Cont

\begin{tabular}{|c|c|c|c|}
\hline \multicolumn{4}{|c|}{ UPREGULATED } \\
\hline \multicolumn{2}{|l|}{ gal+/+ } & \multicolumn{2}{|l|}{ gal-I- } \\
\hline TERM & COUNT & TERM & COUNT \\
\hline $\begin{array}{c}\text { Transmembrane receptor protein tyrosine kinase } \\
\text { signaling pathway }\end{array}$ & 7 & U4 snrna $3^{\prime}$-end processing & 2 \\
\hline Cell-matrix adhesion & 6 & $\begin{array}{c}\text { Nuclear-transcribed mrna catabolic process, } \\
\text { exonucleolytic, } 3^{\prime}-5^{\prime}\end{array}$ & 2 \\
\hline Response to bacterium & 6 & $\begin{array}{l}\text { Exonucleolytic trimming to generate mature } \\
3^{\prime} \text {-end of 5.8S rrna from tricistronic rrna } \\
\text { transcript (SSU-rrna, 5.8S rrna, LSU-rrna) }\end{array}$ & 2 \\
\hline Peptidyl-tyrosine autophosphorylation & 6 & $\begin{array}{l}\text { Nuclear retention of pre-mrna with aberrant } \\
3^{\prime} \text {-ends at the site of transcription }\end{array}$ & 2 \\
\hline Cell chemotaxis & 6 & Glycogen metabolic process & 2 \\
\hline Positive regulation of apoptotic process & 6 & Adrenal gland development & 2 \\
\hline Positive regulation of MAPK cascade & 5 & $\begin{array}{l}\text { Nuclear polyadenylation-dependent trna } \\
\text { catabolic process }\end{array}$ & 2 \\
\hline Regulation of cell growth & 5 & & \\
\hline $\begin{array}{l}\text { Epiboly involved in gastrulation with mouth } \\
\text { forming second }\end{array}$ & 5 & & \\
\hline Immune system process & 4 & & \\
\hline Response to wounding & 4 & & \\
\hline Circadian rhythm & 4 & & \\
\hline Neutrophil chemotaxis & 4 & & \\
\hline Regulation of cell migration & 4 & & \\
\hline Definitive hemopoiesis & 4 & & \\
\hline $\begin{array}{l}\text { Positive regulation of hematopoietic progenitor } \\
\text { cell differentiation }\end{array}$ & 3 & & \\
\hline Activation of MAPK activity & 3 & & \\
\hline Regulation of hematopoietic progenitor cell differentiation & 3 & & \\
\hline Response to glucose & 3 & & \\
\hline Response to cytokine & 3 & & \\
\hline Intracellular sequestering of iron ion & 3 & & \\
\hline Response to heat & 3 & & \\
\hline Iron ion transport & 3 & & \\
\hline Peptide cross-linking & 3 & & \\
\hline Regulation of inflammatory response & 3 & & \\
\hline Response to cadmium ion & 3 & & \\
\hline Macrophage differentiation & 3 & & \\
\hline Response to mechanical stimulus & 3 & & \\
\hline Activation of innate immune response & 2 & & \\
\hline $\begin{array}{c}\text { Regulation of cysteine-type endopeptidase activity } \\
\text { involved in apoptotic process }\end{array}$ & 2 & & \\
\hline Plasminogen activation & 2 & & \\
\hline
\end{tabular}


Table 1. Cont.

\begin{tabular}{|c|c|c|c|}
\hline \multicolumn{4}{|c|}{ DOWNREGULATED } \\
\hline Transport & 35 & Regulation of transcription, DNA-templated & 32 \\
\hline Transmembrane transport & 15 & Transport & 30 \\
\hline Visual perception & 14 & Oxidation-reduction process & 18 \\
\hline Response to stimulus & 13 & Transmembrane transport & 17 \\
\hline DNA replication & 10 & Regulation of cell growth & 6 \\
\hline Cellular response to light stimulus & 8 & Steroid hormone mediated signaling pathway & 6 \\
\hline Phototransduction & 8 & Potassium ion transmembrane transport & 5 \\
\hline Protein-chromophore linkage & 7 & Single organismal cell-cell adhesion & 4 \\
\hline DNA replication initiation & 6 & Neurotransmitter transport & 4 \\
\hline Retina development in camera-type eye & 6 & One-carbon metabolic process & 4 \\
\hline Melanosome organization & 5 & Heart contraction & 4 \\
\hline Microtubule-based process & 5 & Muscle contraction & 3 \\
\hline Developmental pigmentation & 5 & Carbohydrate transport & 3 \\
\hline Erythrocyte differentiation & 4 & Glucose 6-phosphate metabolic process & 2 \\
\hline Embryonic hemopoiesis & 4 & Sodium-dependent phosphate transport & 2 \\
\hline Oxygen transport & 4 & Mitotic G1 DNA damage checkpoint & 2 \\
\hline Mitotic cell cycle & 4 & & \\
\hline Nucleobase-containing compound metabolic process & 4 & & \\
\hline Positive regulation of cell proliferation & 4 & & \\
\hline Spindle assembly & 3 & & \\
\hline Skeletal muscle contraction & 3 & & \\
\hline Response to light stimulus & 3 & & \\
\hline Error-free translation synthesis & 2 & & \\
\hline DNA strand elongation & 2 & & \\
\hline Regulation of hematopoietic stem cell differentiation & 2 & & \\
\hline Melanin biosynthetic process & 2 & & \\
\hline $\begin{array}{l}\text { Detection of chemical stimulus involved in sensory } \\
\text { perception of bitter taste }\end{array}$ & 2 & & \\
\hline $\begin{array}{c}\text { Negative regulation of cysteine-type } \\
\text { endopeptidase activity }\end{array}$ & 2 & & \\
\hline Regulation of G2/M transition of mitotic cell cycle & 2 & & \\
\hline
\end{tabular}

Table 2. Comparisons of affected genes in biological processes in gal+/+ wild-type and gal-/- mutant larvae after $M$. marinum infection. Common genes are marked as grey.

\begin{tabular}{|c|c|}
\hline \multicolumn{2}{|c|}{ Immune Response } \\
\hline gal+/+ & gal-l- \\
\hline $\begin{array}{l}\text { CD74 molecule, major histocompatibility complex, class II invariant } \\
\text { chain a }(c d 74 a)\end{array}$ & Fas ligand (TNF superfamily, member 6)(faslg) \\
\hline CX chemokine ligand 34b, duplicate 11(cxl34b.11) & chemokine (C-C motif) ligand 19a, tandem duplicate 2(ccl19a.2) \\
\hline Fas cell surface death receptor(fas) & chemokine CCL-C17a(LOC100002392) \\
\hline chemokine (C-C motif) ligand 19a, tandem duplicate 1(ccl19a.1) & complement component $7 a(c 7 a)$ \\
\hline chemokine (C-C motif) ligand 36, duplicate 1(ccl36.1) & interleukin 10(il10) \\
\hline chemokine (C-X-C motif) ligand 11, duplicate 1(cxcl11.1) & si:rp71-1i20.2(si:rp71-1i20.2) \\
\hline
\end{tabular}


Table 2. Cont.

\begin{tabular}{|c|c|}
\hline \multicolumn{2}{|c|}{ Immune Response } \\
\hline gal+/+ & gal-l- \\
\hline chemokine (C-X-C motif) ligand 11, duplicate 7(cxcl11.7) & tumor necrosis factor (ligand) superfamily, member 10(tnfsf10) \\
\hline chemokine (C-X-C motif) ligand 19(cxcl19) & uncharacterized LOC101882211(LOC101882211) \\
\hline chemokine (C-X-C motif) ligand 8b, duplicate 1(cxcl8b.1) & $z m p: 0000000652(z m p: 0000000652)$ \\
\hline \multicolumn{2}{|l|}{ complement factor properdin(cfp) } \\
\hline \multicolumn{2}{|l|}{ interleukin 4(il4) } \\
\hline \multicolumn{2}{|l|}{ lymphocyte cytosolic protein $2 a(l c p 2 a)$} \\
\hline \multicolumn{2}{|l|}{ negative regulator of reactive oxygen species(nrros) } \\
\hline \multicolumn{2}{|l|}{ nuclear factor, interleukin 3 regulated(nfil3) } \\
\hline \multicolumn{2}{|l|}{ proteoglycan $4 b($ prg $4 b)$} \\
\hline \multicolumn{2}{|l|}{$\begin{array}{l}\text { serpin peptidase inhibitor, clade E (nexin, plasminogen activator } \\
\text { inhibitor type 1), member 1(serpine1) }\end{array}$} \\
\hline \multicolumn{2}{|l|}{ si:ch211-137i24.12(si:ch211-137i24.12) } \\
\hline \multicolumn{2}{|l|}{ si:ch73-27e22.6(si:ch73-27e22.6) } \\
\hline \multicolumn{2}{|l|}{ si:ch73-27e22.7(si:ch73-27e22.7) } \\
\hline \multicolumn{2}{|l|}{ si:ch73-44m9.1(si:ch73-44m9.1) } \\
\hline \multicolumn{2}{|l|}{ si:dkey-19a16.4(si:dkey-19a16.4) } \\
\hline \multicolumn{2}{|l|}{ si:dkey-253d23.4(si:dkey-253d23.4) } \\
\hline \multicolumn{2}{|l|}{ si:rp71-36a1.1(si:rp71-36a1.1) } \\
\hline \multicolumn{2}{|l|}{ titin-like(LOC101883412) } \\
\hline \multicolumn{2}{|l|}{ tumor necrosis factor (ligand) superfamily, member 11(tnfsf11) } \\
\hline \multicolumn{2}{|l|}{ tumor necrosis factor receptor superfamily, member $1 B($ tnfrsf $1 b)$} \\
\hline \multicolumn{2}{|l|}{ tumor necrosis factor, alpha-induced protein 3(tnfaip3) } \\
\hline \multicolumn{2}{|l|}{ uncharacterized LOC101883645(LOC101883645) } \\
\hline \multicolumn{2}{|l|}{ uncharacterized LOC101885444(LOC101885444) } \\
\hline$z g c: 153759(z g c: 153759)$ & \\
\hline
\end{tabular}

\section{Inflammatory Response}

C5a anaphylatoxin chemotactic receptor(c5ar1) chemokine (C-C motif) ligand 19a, tandem duplicate 2(ccl19a.2)

CD40 molecule, TNF receptor superfamily member 5(cd40) interleukin 10(il10)

E74-like factor 3 (ets domain transcription factor, epithelial-specific) (elf3)

Fas cell surface death receptor(fas) toll-like receptor 22(tlr22)

\begin{tabular}{c}
\hline Fas cell surface death receptor(fas) \\
\hline chemokine (C-C motif) ligand 19a, tandem duplicate 1(ccl19a.1) \\
\hline chemokine (C-X-C motif) ligand 11, duplicate 1(cxcl11.1) \\
\hline chemokine (C-X-C motif) ligand 11, duplicate 7(cxcl11.7) \\
\hline chemokine (C-X-C motif) ligand 19(cxcl19) \\
\hline colony stimulating factor 1 receptor, a(csf1ra) \\
\hline myeloid differentiation primary response 88(myd88) \\
\hline negative regulator of reactive oxygen species (nrros) \\
\hline nitric oxide synthase $2 a$, inducible(nos2a) \\
\hline prostaglandin E receptor $2 b$ (subtype EP2)(ptger2b)
\end{tabular}


Table 2. Cont.

\section{Inflammatory Response}

serum/glucocorticoid regulated kinase 1(sgk1)

$$
\text { toll-like receptor } 5 a(t \operatorname{lr} 5 a)
$$

tumor necrosis factor receptor superfamily, member $1 B($ tnfrsf $1 b)$

v-rel avian reticuloendotheliosis viral oncogene homolog(rel)

$$
z g c: 153759(z g c: 153759)
$$

\section{Response to Bacterium}

CCAAT/enhancer binding protein (C/EBP), beta(cebpb) matrix metallopeptidase 9( $\mathrm{mmp9)}$ coagulation factor $V(f 5)$ toll-like receptor 22(tlr22)

hepcidin antimicrobial peptide(hamp) transferrin-a(tfa)

immunoresponsive gene 1, like(irg1l)

interleukin-1 receptor-associated kinase 4(irak4)

leukocyte cell-derived chemotaxin 2 like(lect2l)

(A)

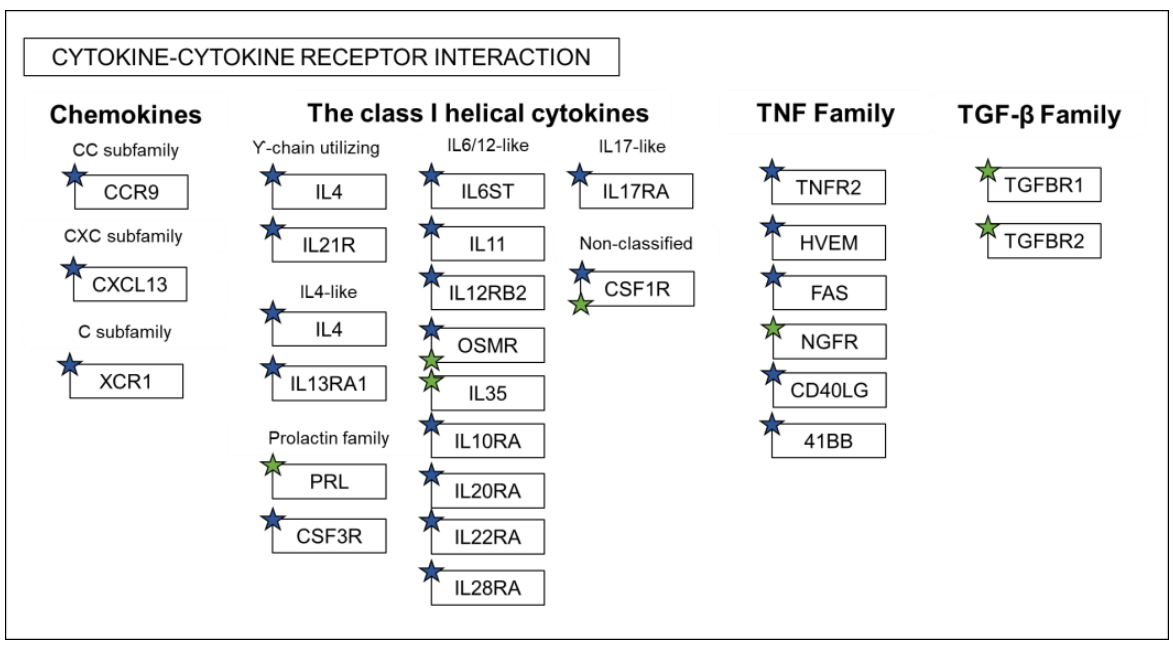

(B)

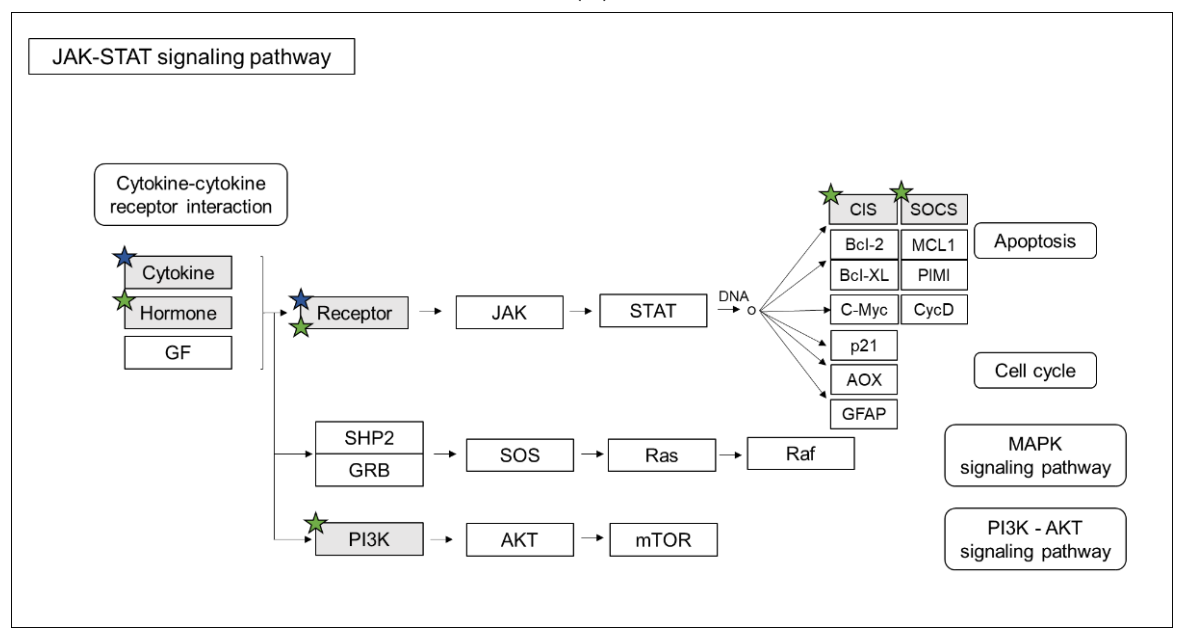

Figure 5. Pathway analysis. Comparison of regulated genes between $g a l+/+$ and $g a l-/-$ larvae after M. marinum infection in KEGG Pathways: (A) Cytokine-cytokine receptor interaction and (B) JAK-STAT signaling pathway. Blue stars indicate genes regulated in $g a l+/+$, while green in $g a l-/-$. 
We also checked if the expression of galanin receptors, galr1a, galr1b, galr2a and galr2b, changed in the gal-/- mutants before and after M. marinum infection, as well as in the $g a l+/+$ larvae after infection. There is, however, no significant difference in the expression levels between the groups (Table S2).

Collectively, these data showed that galanin deficiency led to significant changes in the expression of different genes that affects various pathways and processes in an organism, although most of them are downregulated.

\section{Discussion}

Many neuropeptides such as substance P (SP), neuropeptide Y (NPY), the vasoactive intestinal peptide (VIP) and galanin are not only expressed in nervous system, but also in leukocytes [49]. The neuropeptide galanin was first discovered 30 years ago. The galanin family has been shown to be involved in a wide variety of biological and pathological functions. Although galanin is a well-known neuropeptide, there is not much information about its function in the immune response. Interestingly, another member of the family, GMAP, shows anti-microbial activities and is hypothesized to be part of the innate immune system, since it suppresses Candida albicans growth and significantly reduces growth in six out of seven Candida strains [50].

In this study, we generated gal-/- mutant zebrafish larvae, which also knocks out GMAP expression. The larvae were infected with two bacteria, M. marinum or S. aureus, which represent pathogens able to develop drug resistance and are therefore alarming in public health problems. It has previously been shown in the murine model that galanin is connected with inflammatory processes in various organs, and it had been reported e.g., that galanin receptor 3 is involved in skin inflammation in mice [51]. Our results indicated that the knockout of galanin expression resulted in a higher bacterial burden and mortality during a systemic caudal vein and yolk infection with both M. marinum and $S$. aureus. We also demonstrated that the administration of the exogenous galanin analogue NAX 5055 into galanin-deficient larvae reduced the progression of infection and lowered mortality after caudal vein infection with both pathogens; however, the treatment was barely effective after yolk infection with $S$. aureus, where mortality exceeded $80 \%$ after 16 hpi. While $M$. marinum is a natural zebrafish pathogen, $S$. aureus infection is an experimental model to study bacterial burden and immune response. Infection with the pathogen was successfully established previously; however, the injection was performed at 30hpf [38]. During our study, we decided to infect zebrafish embryos with both bacteria at the same time point, which resulted in severe staphylococcal infection, probably due to rapid bacterial proliferation before the onset of cellular immunity in zebrafish embryos. It was not unusual, since yolk infection led to a rapid progress of infection and mortality after Cronobacter turicensis [52] or S. typhimurium [53] injection. Additionally, NAX 5055 treatment restored the expression of the pro-inflammatory cytokines and general response to the infection.

Based on the findings, we wanted to check the expression of the most important proinflammatory cytokines, namely $i l 1 b$, tnfa and cxcl8a. We demonstrated that $t n f a$ was downregulated in the gal-/- mutant, both after M. marinum and S. aureus infection. TNF $\alpha$ acts as a membrane-bound protein and plays a central role in inflammation and pathogenesis of various diseases [54]. In zebrafish, Tnfa is an already well-known cytokine that is upregulated during M. marinum infection, and the reduction of tnfa expression leads to an increased bacterial burden and death of macrophages [55]. Interestingly, upregulation of its expression also results in more severe progression of the disease, showing that the right balance in its pro-inflammatory activity is crucial for proper control of the infection [56]. Moreover, Tnfa in zebrafish is responsible for recruiting leukocytes to the site of infection and chemokines production, rather than phagocyte activation [57].

Similar to $\operatorname{tnfa}$, we found illb to be downregulated in the infected gal-/- mutant. Interleukin 1 beta (IL1B) is a crucial activator of immune cells, as it is upregulated during M. tuberculosis and M. marinum infection in the zebrafish and is strictly connected with 
tnfa activity [58]. Il1b is required for a host response to the infection. It is secreted as an active cytokine from its inactive precursor where an inflammatory response occurs. It is conserved between mammals and zebrafish and its expression is upregulated in zebrafish larvae infected with various bacteria such as S. typhymurium or E. tarda [59-62]. Cxcl8a is also an important neutrophil activator and is responsible for their recruitment to the infection site [63]. Galanin expression was found on polymorphonuclear neutrophil (PMN) as it increases their sensitivity to the chemokine CXCL8 [61]. As a result, galanin treatment significantly enhanced the response PMNs of human and mice PMN to CXCL8 [64]. We found cxcl8a to be significantly downregulated in the gal-/- mutant after both $M$. marinum and S. aureus infection, compared to the control infected group and significantly upregulated after NAX 5055 treatment in M. marinum infected larvae. Moreover, we tested the expression of $\mathrm{irg} 1 \mathrm{l}$, an immunoresponsive gene that is a homolog of the same gene known in mice [60], which was also downregulated in the gal-/- mutant larvae after infection with both pathogens. Our study shows that galanin acts pro-inflammatory, while its absence downregulates the expression of particular cytokines. However, not much is known about the role and mechanism of galanin in these processes.

Galanin expression has an impact on macrophages and neutrophils [59,60]. Previous research showed that exposure to exogenous galanin affected the cytokine/chemokine expression of macrophages [64]. Galanin was also shown to act as an immunomodulatory peptide, since it can sensitize polymorphonuclear neutrophils towards pro-inflammatory cytokines in humans and mice [65]. Macrophages play a huge role in the development of granuloma. During our research, we did not focus on the immune cells function; however, we noticed that galanin knockout led to higher number of macrophages, which was reduced by NAX 5055 treatment (Figure S2). This observation can be linked to the granuloma formation that was also increased in the gal-/- mutants. Interestingly, treatment with NAX5055 in the gal+/+ wild-type did not have any significant impact on the number of fluorescent macrophages. Infection with S. aureus affects both macrophages and neutrophils, the number of which usually increases, except for an overwhelming infection that results in leukopenia and increased mortality [36]. Looking at the progress of S. aureus infection in gal-/- larvae, it is possible that high mortality is connected to the affected neutrophil function that needs further research. The alteration of chemokine expression and secretion by galanin indicates a role of galanin in immune cell migration, and this function of galanin is not fully studied yet [64].

To understand the molecular background of the galanin knockout, we performed whole-larvae RNA sequencing, both in non-infected fish and after M. marinum infection. We compared and divided the larvae into two groups gal+/+ with gal-/- both after mycobacterial infection. Significantly changed genes from both infected groups were analyzed using the DAVID functional annotation tool. In the gal+/+ wild-type group, most of the affected pathways were connected to the immune response and found to be upregulated. These findings in the gal+/+ wild-type group correlate with previous study by Benard et al. (2016) [63], where at 4 dpi a similar number of genes were changed due to infection (1165 upregulated and 748 downregulated) and those connected to immunity were upregulated. It has also been shown that a large number of affected genes were immune-related, especially at $4 \mathrm{dpi}$ [63]. However, in the gal-/- mutant larvae, we found that significantly less immune-related genes were changed after infection; moreover, significantly affected KEGG pathways were downregulated. Two KEGG pathways were shared between the two groups: The Cytokine-cytokine receptor interaction and the JAK-STAT signaling pathway; however, only two genes (osmr and csf1r) were common for both groups. A similar finding was observed among common biological processes. Only three of them were shared between the two groups; however, only one gene (ccl19a.1) was common. It indicates that galanin knockdown resulted in a markedly different reaction to the pathogen and immune response compared to the control group, even though the same pathways and processes are involved in the infection. In the gal-/- mutant larvae, the MAPK signaling pathway, cytokines activity and JAK-STAT pathways were regulated, which partially correlates with previous 
findings in a galanin receptor knockout model, where galanin receptor 3 knockout in mice (GAL3-KO) resulted in lower expression of IL-17A, IL-22, IL-23 and TNF- $\alpha$ [51]. Another study showed that galanin modulates cytokine/chemokine expression in macrophages, which depended on the cell line and additional treatment [65]. JAK-STAT signaling pathway plays a significant role during bacterial infection. A canonical JAK/STAT pathway has been characterized from studies in cytokine signaling in mammalian cells [66]. In zebrafish, both JAK and STAT proteins have been characterized as well [67]. There are not many reports about galanin association with the JAK/STAT signaling pathway; however, there are studies that show correlation between galanin production and prolactin production via JAK-STAT [68]. In our work, however, JAK/STAT signaling pathways were upregulated in the gal+/+ control larvae with 13 regulated genes, while they were downregulated in the gal-/- mutants with 5 affected genes. Mitogen-activated protein kinases (MAPKs) are involved in relaying extracellular signals to intracellular responses. Several studies suggest that the MAPK pathway affects mycobacterial pathogenesis [69]. It was shown that the intracellular growth of Mycobacterium avium in macrophages depends on the extent of MAPK phosphorylation, indicating a role of the pathway in macrophage activation. Additionally, the activation of MAPK is induced by infection with M. tuberculosis and is essential for the mycobacterium-induced production of pro-inflammatory cytokines [69]. Our findings showed that compared to the infected gal+/+ wild-type, where immune-related genes and processes were upregulated, in the gal-/- mutants, the situation was opposite. Among biological processes, we determined terms connected to immunity such as Immune response, Response to bacterium and Inflammatory response; however, most of the GO terms were identified as metabolic processes. In conclusion, galanin knockout attenuates immune response compared to the wild-type siblings revealing the immunostimulatory role of galanin in bacterial infection.

In summary, we explored the role of galanin during bacterial infection in the zebrafish larvae using two pathogens that are commonly used in zebrafish research, $M$. marinum and S. aureus. We discovered that galanin expression is crucial for the ability to control the infection by the innate immune system, as well as that galanin knockout leads to immune suppression. Our results correspond to previous findings in murine models, showing complexity of interactions between immune- and neuroendocrine systems. Interestingly, galanin is suggested to have an anti-inflammatory function in some situations and a proinflammatory function in others depending on the conditions. The literature is controversial and currently not conclusive. This could be due to the complexity of the metabolic network signaling and interactions between galanin and its receptor. Additional studies are needed to fully understand these processes and improve current therapies against drug resistant bacterial infections.

Supplementary Materials: The following are available online at https://www.mdpi.com/article/10 .3390/cells10082011/s1, Figure S1: (A)(B) Bacterial burden in non-infected wild-type larvae, infected wild-type larvae and, infected and non-infected, wild-type larvae treated with NAX 5055 after (A) M. marinum yolk or (B) caudal vein infection. Data is combined from three biological replicates. ${ }^{* *} p<0.01 ;{ }^{* * *} p<0.001 ;{ }^{* * *} p<0.0001 ;$ ns, non-significant. Figure S2: Quantification of macrophages in the $g a l+/+\operatorname{Tg}(m p e g 1: E G F P)(+/+)$ and gal-/- $\operatorname{Tg}($ mpeg1:EGFP) zebrafish larvae. Total fluorescence of gal+/+ Tg(mpeg1:EGFP) (+/+) and gal-/- Tg(mpeg1:EGFP) (-/-) without or with (+/+ NAX; -/NAX) NAX 5055 treatment. Data is combined from three biological replicates ( $\mathrm{n}=10$ larvae/group). * $p<0.05$. Table S1: Primer sequences and Genbank accessions for genes analyzed in this study. Table S2: Expression of galanin receptors in gal+/+ and gal-/- after M. marinum infection and gal-/without infection., Table S3: Genes significantly regulated in gal+/+ larvae after M. marinum infection. Table S4: Genes significantly regulated in gal-/- larvae after M. marinum infection. 
Author Contributions: Conceptualization, P.P. and T.K.P.; methodology, P.P. and T.K.P.; validation, N.N. and A.P.; formal analysis, N.N.; investigation, N.N., T.K.P. and P.P.; resources, N.N. and H.P.S.; data curation, N.N. and T.K.P.; writing-original draft preparation, N.N.; writing-review and editing, N.N., T.K.P., A.P., K.R., W.S. and P.P.; visualization, N.N., T.K.P. and P.P.; supervision, T.K.P., W.S., H.P.S. and P.P.; project administration, A.P.; funding acquisition, N.N. All authors have read and agreed to the published version of the manuscript.

Funding: This study was funded by the Polish National Science Centre Education, grant PRELUDIUM 11, No. 2016/21/N/NZ6/01162. Tomasz K. Prajsnar was supported by Polish National Agency for Academic Exchange under Polish Returns 2019 project (Grant number: PPN/PPO/2019/ $1 / 00029 / \mathrm{U} / 0001)$. The project was financially supported by the Minister of Science and Higher Education in the range of the program entitled "Regional Initiative of Excellence" for the years 2019-2022, Project No. 010/RID/2018/19, amount of funding 12,000,000 PLN.

Institutional Review Board Statement: All fish are housed in the fish facility of the Laboratory of Genomics and Transcriptomics, the University of Warmia and Mazury in Olsztyn, Olsztyn, Poland, which was built in accordance with the local animal welfare standards. All animal procedures were performed in accordance with the Polish and European Union animal welfare guidelines. According to the European Directive 2010/63/EU and Polish law regulations O.J. of 2015, item 266, all procedures performed in the present study including the use of early life-stage zebrafish and euthanasia do not require Ethics Committee permissions. The facility has approval to keep and breed genetically modified zebrafish lines issued by the Polish Ministry of Environment, decision number $127 / 2017$. The culture of zebrafish with mutations in immune genes was approved by the local animal welfare committee (DEC) of the University of Leiden (protocol 14,198). All protocols adhered to the international guidelines specified by the EU Animal Protection Directive 2010/63/EU.

Informed Consent Statement: Not applicable.

Data Availability Statement: The raw data presented in this study are available as non-published materials.

Conflicts of Interest: The authors declare no conflict of interest.

\section{References}

1. Gonzalez-Rey, E.; Chorny, A.; Delgado, M. Regulation of immune tolerance by anti-inflammatory neuropeptides. Nat. Rev. Immunol. 2007, 7, 52-63. [CrossRef]

2. Rivest, S. Interactions between the immune and neuroendocrine systems. Prog. Brain Res. 2010, 181, 43-53.

3. Sterner-Kock, A.; Braun, R.K.; van der Vliet, A.; Schrenzel, M.D.; McDonald, R.J.; Kabbur, M.B.; Vulliet, P.R.; Hyde, D.M. Substance P primes the formation of hydrogen peroxide and nitric oxide in human neutrophils. J. Leukoc. Biol. 1999, 65, 834-840. [CrossRef] [PubMed]

4. Kinhult, J.; Egesten, A.; Uddman, R.; Cardell, L.O. PACAP enhances the expression of CD11b, CD66b andCD63 in human neutrophils. Peptides 2002, 23, 1735-1739. [CrossRef]

5. Monneret, G.; Arpin, M.; Venet, F.; Maghni, K.; Debard, A.L.; Pachot, A.; Lepape, A.; Bienvenu, J. Calcitonin gene related peptide and N-procalcitonin modulate CD11b upregulation in lipopolysaccharide activated monocytes and neutrophils. Intensive Care Med. 2003, 29, 923-928. [CrossRef] [PubMed]

6. Dimitrijevic, M.; Stanojevic, S.; Micic, S.; Vujic, V.; Kovacevic-Jovanovic, V.; Mitic, K.; von Horsten, S.; Kosec, D. Neuropeptide Y (NPY) modulates oxidative burst and nitric oxide production in carrageenan-elicited granulocytes from rat air pouch. Peptides 2006, 27, 3208-3215. [CrossRef]

7. Tatemoto, K.; Rokaeus, A.; Jornvall, H.; McDonald, T.J.; Mutt, V. Galanin-A novel biologically active peptide from porcine intestine. FEBS Lett. 1983, 164, 124-128. [CrossRef]

8. Kroeger, D.; Absi, G.; Gagliardi, C.; Bandaru, S.S.; Madara, J.C.; Ferrari, L.L.; Arrigoni, E.; Münzberg, H.; Scammell, T.E.; Saper, C.B.; et al. Galanin neurons in the ventrolateral pre-optic area promote sleep and heat loss in mice. Nat. Commun. 2018, 9, 4129. [CrossRef]

9. Lang, R.; Gundlach, A.L.; Holmes, F.E.; Hobson, S.A.; Wynick, D.; Hökfelt, T.; Kofler, B. Physiology, signaling, and pharmacology of galanin peptides and receptors: Three decades of emerging diversity. Pharm. Rev. 2015, 67, 118-175. [CrossRef]

10. Podlasz, P.; Wasowicz, K. Neurochemical characteristics of paracervical ganglion in the pig. Veterinární Med. 2008, 53, 135. [CrossRef]

11. Podlasz, P.; Sallinen, V.; Chen, Y.C.; Kudo, H.; Fedorowska, N.; Panula, P. Galanin gene expression and effects of its knock-down on the development of the nervous system in larval zebrafish. J. Comp. Neurol. 2012, 520, 3846-3862. [CrossRef] [PubMed]

12. Fang, P.; Yu, M.; Guo, L.; Bo, P.; Zhang, Z.; Shi, M. Galanin and its receptors: A novel strategy for appetite control and obesity therapy. Peptides. 2012, 36, 331-339. [CrossRef] [PubMed] 
13. Matkowskyj, K.A.; Nathaniel, R.; Prasad, R.; Weihrauch, D.; Rao, M.; Benya, R.V. Galanin contributes to the excess colonic fluid secretion observed in dextran sulfate sodium murine colitis. Inflamm. Bowel Dis. 2004, 10, 408-416. [CrossRef] [PubMed]

14. Talero, E.; Sánchez-Fidalgo, S.; Calvo, J.R.; Motilva, V. Chronic administration of galanin attenuates the TNBS-induced colitis in rats. Regul. Pept. 2007, 141, 96-104. [CrossRef]

15. Schmidhuber, S.M.; Rauch, I.; Kofler, B.; Brain, S.D. Evidence that the modulatory effect of galanin on inflammatory edema formation is mediated by the galanin receptor 3 in the murine microvasculature. J. Mol. Neurosci. 2009, 37, 177-181. [CrossRef]

16. Pilmane, M.; Shine, J.; Iismaa, T.P. Distribution of galanin immunoreactivity in the bronchi of humans with tuberculosis. Ann. N. Y. Acad. Sci. 1998, 863, 445-449. [CrossRef] [PubMed]

17. Jurkowski, W.; Yazdi, S.; Elofsson, A. Ligand binding properties of human galanin receptors. Mol. Membr. Biol. 2013, 30, 206-216. [CrossRef] [PubMed]

18. Liu, Z.; Xu, Y.; Zhang, S. Evolution of galanin receptor genes: Insights from the deuterostome genomes. J. Biomol. Stuct. Dyn. 2010, 28, 97-106. [CrossRef]

19. Eskova, A.; Frohnhöfer, H.G.; Nüsslein-Volhard, C.; Irion, U. Galanin Signaling in the Brain Regulates Color Pattern Formation in Zebrafish. Curr. Biol. 2020, 30, 298-303. [CrossRef]

20. Li, L.; Wei, S.; Huang, Q.; Feng, D.; Zhang, S.; Liu, Z. A novel galanin receptor 1a gene in zebrafish: Tissue distribution, developmental expression and roles in nutrition regulation. Comp. Biochem. Physiology. Part B Biochem. Mol. Biol. 2013, 164, 159-167. [CrossRef]

21. Kim, E.; Jeong, I.; Kim, S.; Kim, H.K.; Lee, D.W.; Kim, B.; Seong, J.Y.; Bae, Y.K.; Ryu, J.H.; Park, H.C. Distribution of galanin receptor $2 b$ neurons and interaction with galanin in the zebrafish central nervous system. Neurosci. Lett. 2016, 628, 153-160. [CrossRef] [PubMed]

22. Varshney, G.K.; Pei, W.; LaFave, M.C.; Idol, J.; Xu, L.; Gallardo, V.; Carrington, B.; Bishop, K.; Jones, M.; Li, M.; et al. Highthroughput gene targeting and phenotyping in zebrafish using CRISPR/Cas9. Genome Res. 2015, 25, 1030-1042. [CrossRef]

23. Howe, K.; Clark, M.D.; Torroja, C.F.; Torrance, J.; Berthelot, C.; Muffato, M.; Collins, J.E.; Humphray, S.; McLaren, K.; Matthews, L.; et al. The zebrafish reference genome sequence and its relationship to the human genome. Nature 2013, 7446, 498-503. [CrossRef]

24. Panula, P.; Sallinen, V.; Sundvik, M.; Kolehmainen, J.; Torkko, V.; Tiittula, A.; Moshnyakov, M.; Podlasz, P. Modulatory neurotransmitter systems and behavior: Towards zebrafish models of neurodegenerative diseases. Zebrafish 2006, 3, 235-247. [CrossRef]

25. Tulotta, C.; He, S.; van der Ent, W.; Chen, L.; Groenewoud, A.; Spaink, H.P.; Snaar-Jagalska, B.E. Imaging Cancer Angiogenesis and Metastasis in a Zebrafish Embryo Model. Adv. Exp. Med. Biol. 2016, 916, 239-263. [PubMed]

26. Veneman, W.J.; Marín-Juez, R.; de Soneville, J.; Ordas, A.; Jong-Raadsen, S.; Meijer, A.H.; Spaink, H.P. Establishment and optimization of a high throughput setup to study Staphylococcus epidermidis and Mycobacterium marinum infection as a model for drug discovery. J. Vis. Exp. 2014, 88, e51649. [CrossRef] [PubMed]

27. Habu, A.; Ohishi, T.; Mihara, S.; Ohkubo, R.; Hong, Y.M.; Mochizuki, T.; Yanaihara, N. Isolation and Sequence Determination of Galanin from the Pituitary of Yellowfin Tuna. Biomed. Res. 1994, 15, 357-362. [CrossRef]

28. World Health Organization. WHO Global Tuberculosis Report 2020; Licence: CC BY-NC-SA 3.0 IGO; World Health Organization: Geneva, Switzerland, 2020.

29. Ramakrishnan, L. Revisiting the role of the granuloma in tuberculosis. Nat. Rev. Immunol. 2012, 12, 352-366. [CrossRef]

30. Josse, J.; Velard, F.; Gangloff, S.C. Staphylococcus aureus vs. Osteoblast: Relationship and Consequences in Osteomyelitis. Front. Cell Infect. Microbiol. 2015, 26, 5:85. [CrossRef]

31. Thomer, L.; Schneewind, O.; Missiakas, D. Pathogenesis of Staphylococcus aureus Bloodstream Infections. Annu. Rev. Pathol. 2016, 11, 343-364. [CrossRef]

32. Keynan, Y.; Rubinstein, E. Staphylococcus aureus bacteremia, risk factors, complications, and management. Crit. Care Clin. 2013, 29, 547-562. [CrossRef] [PubMed]

33. Torraca, V.; Mostowy, S. Zebrafish Infection: From Pathogenesis to Cell Biology. Trends Cell Biol. 2018, 28, 143-156. [CrossRef] [PubMed]

34. Davis, J.M.; Clay, H.; Lewis, J.L.; Ghori, N.; Herbomel, P.; Ramakrishnan, L. Real-time visualization of mycobacterium-macrophage interactions leading to initiation of granuloma formation in zebrafish embryos. Immunity 2002, 17, 693-702. [CrossRef]

35. Prouty, M.G.; Correa, N.E.; Barker, L.P.; Jagadeeswaran, P.; Klose, K.E. Zebrafish-Mycobacterium marinum model for mycobacterial pathogenesis. FEMS Microbiol. Lett. 2003, 25, 177-182. [CrossRef]

36. Novoa, B.; Figueras, A. Zebrafish: Model for the study of inflammation and the innate immune response to infectious diseases. Adv. Exp. Med. Biol. 2012, 946, 253-275. [PubMed]

37. Meijer, A.H. Protection and pathology in TB: Learning from the zebrafish model. Semin. Immunopathol. 2016, 38, 261-273. [CrossRef]

38. Prajsnar, T.K.; Cunliffe, V.T.; Foster, S.J.; Renshaw, S.A. A novel vertebrate model of Staphylococcus aureus infection reveals phagocyte-dependent resistance of zebrafish to non-host specialized pathogens. Cell Microbiol. 2008, 11, 2312-2325. [CrossRef]

39. White, H.S.; Scholl, E.A.; Klein, B.D.; Flynn, S.P.; Pruess, T.H.; Green, B.R.; Zhang, L.; Bulaj, B. Developing novel antiepileptic drugs: Characterization of NAX 5055, a systemically-active galanin analog, in epilepsy models. Neurotherapeutics 2009, 6, 372-380. [CrossRef] 
40. Bulaj, G.; Green, B.R.; Lee, H.K.; Robertson, C.R.; White, K.; Zhang, L.; Sochanska, M.; Flynn, S.P.; Scholl, E.A.; Pruess, T.H.; et al. Design, synthesis and characterization of high-affinity, systemically-active galanin analogs with potent anticonvulsant activities. J. Med. Chem. 2008, 51, 8038-8047. [CrossRef]

41. Hwang, W.Y.; Fu, Y.; Reyon, D.; Maeder, M.L.; Kaini, P.; Sander, J.D.; Joung, J.K.; Peterson, R.T.; Yeh, J.R. Heritable and precise zebrafish genome editing using a CRISPR-Cas system. PLoS ONE. 2013, 8, e68708. [CrossRef]

42. Kimmel, C.B.; Ballard, W.W.; Kimmel, S.R.; Ullmann, B.; Schilling, T.F. Stages of embryonic development of the zebrafish. Dev. Dyn. 1995, 203, 253-310. [CrossRef]

43. Benard, E.L.; van der Sar, A.M.; Ellett, F.; Lieschke, G.J.; Spaink, H.P.; Meijer, A.H. Infection of Zebrafish Embryos with Intracellular Bacterial Pathogens. J. Vis. Exp. 2012, 61, 3781. [CrossRef] [PubMed]

44. Boldock, E.; Surewaard, B.G.J.; Shamarina, D.; Na, M.; Fei, Y.; Ali, A.; Williams, A.; Pollitt, E.J.G.; Szkuta, P.; Morris, P.; et al. Human skin commensals augment Staphylococcus aureus pathogenesis. Nat. Microbiol. 2018, 8, 881-890. [CrossRef] [PubMed]

45. Stoop, E.J.; Schipper, T.; Rosendahl Huber, S.K.; Nezhinsky, A.E.; Verbeek, F.J.; Gurcha, S.S.; Besra, G.S.; Vandenbroucke-Grauls, C.M.; Bitter, W.; van der Sar, A.M. Zebrafish embryo screen for mycobacterial genes involved in the initiation of granuloma formation reveals a newly identified ESX-1 component. Dis. Model. Mech. 2011, 4, 526-536. [CrossRef]

46. Rotman, J.; van Gils, W.; Butler, D.; Spaink, H.P.; Meijer, A.H. Rapid screening of innate immune gene expression in zebrafish using reverse transcription-Multiplex ligation-dependent probe amplification. BMC Res. Notes. 2011, 15, 196. [CrossRef]

47. Livak, K.J.; Schmittgen, T.D. Analysis of relative gene expression data using real-time quantitative PCR and the 2 (-Delta Delta C(T)) Method. Methods 2001, 25, 402-408. [CrossRef]

48. Veneman, W.J.; de Sonneville, J.; van der Kolk, K.J.; Ordas, A.; Al-Ars, Z.; Meijer, A.H.; Spaink, H.P. Analysis of RNAseq datasets from a comparative infectious disease zebrafish model using GeneTiles bioinformatics. Immunogenetics 2015, 67, 135-147. [CrossRef] [PubMed]

49. Grant, A. Leukocytes and neurogenic inflammation. Inflammopharmacology 2011, 9, 403-420. [CrossRef]

50. Rauch, I.; Lundström, L.; Hell, M.; Sperl, W.; Kofler, B. Galanin message-associated peptide suppresses growth and the buddedto-hyphal-form transition of Candida albicans. Antimicrob. Agents Chemother. 2007, 51, 4167-4170. [CrossRef]

51. Locker, F.; Vidali, S.; Holub, B.S.; Stockinger, J.; Brunner, S.M.; Ebner, S.; Koller, A.; Trost, A.; Reitsamer, H.A.; Schwarzenbacher, D.; et al. Lack of Galanin Receptor 3 Alleviates Psoriasis by Altering Vascularization, Immune Cell Infiltration, and Cytokine Expression. J. Investig. Dermatol. 2018, 138, 199-207. [CrossRef]

52. Fehr, A.; Eshwar, A.K.; Neuhauss, S.C.; Ruetten, M.; Lehner, A.; Vaughan, L. Evaluation of zebrafish as a model to study the pathogenesis of the opportunistic pathogen Cronobacter turicensis. Emerg. Microbes Infect. 2015, 5, e29.

53. van der Sar, A.M.; Musters, R.J.; van Eeden, F.J.; Appelmelk, B.J.; Vandenbroucke-Grauls, C.M.; Bitter, W. Zebrafish embryos as a model host for the real time analysis of Salmonella typhimurium infections. Cell Microbiol. 2003, 9, 601-611. [CrossRef] [PubMed]

54. Bradley, J.R. TNF-mediated inflammatory disease. J. Pathol. 2008, 214, 149-160. [CrossRef]

55. Clay, H.; Volkman, H.E.; Ramakrishnan, L. Tumor necrosis factor signaling mediates resistance to mycobacteria by inhibiting bacterial growth and macrophage death. Immunity 2008, 29, 283-294. [CrossRef] [PubMed]

56. Tobin, D.M.; Vary, J.C., Jr.; Ray, J.P.; Walsh, G.S.; Dunstan, S.J.; Bang, N.D.; Hagge, D.A.; Khadge, S.; King, M.C.; Hawn, T.R.; et al. The lta4h locus modulates susceptibility to mycobacterial infection in zebrafish and humans. Cell 2010, 140, 717-730. [CrossRef]

57. Roca, F.J.; Mulero, I.; López-Muñoz, A.; Sepulcre, M.P.; Renshaw, S.A.; Meseguer, J.; Mulero, V. Evolution of the inflammatory response in vertebrates: Fish TNF-alpha is a powerful activator of endothelial cells but hardly activates phagocytes. J. Immunol. 2008, 181, 5071-5081. [CrossRef]

58. Di Paolo, N.C.; Shafiani, S.; Day, T.; Papayannopoulou, T.; Russell, D.W.; Iwakura, Y.; Sherman, D.; Urdahl, K.; Shayakhmetov, D.M. Interdependence between interleukin-1 and tumor necrosis factor regulates TNF-dependent control of Mycobacterium tuberculosis infection. Immunity 2015, 43, 1125-1136. [CrossRef]

59. Oehlers, S.H.; Flores, M.V.; Hall, C.J.; O’Toole, R.; Swift, S.; Crosier, K.E.; Crosier, P.S. Expression of zebrafish cxcl8 (interleukin-8) and its receptors during development and in response to immune stimulation. Dev. Comp. Immunol. 2010, 34, 352-359. [CrossRef]

60. van Soest, J.J.; Stockhammer, O.W.; Ordas, A.; Bloemberg, G.V.; Spaink, H.P.; Meijer, A.H. Comparison of static immersion and intravenous injection systems for exposure of zebrafish embryos to the natural pathogen Edwardsiella tarda. BMC Immunol. 2011, 17, 58. [CrossRef] [PubMed]

61. Stockhammer, O.W.; Zakrzewska, A.; Hegedûs, Z.; Spaink, H.P.; Meijer, A.H. Transcriptome profiling and functional analyses of the zebrafish embryonic innate immune response to Salmonella infection. J. Immunol. 2009, 182, 5641-5653. [CrossRef]

62. de Oliveira, S.; Reyes-Aldasoro, C.C.; Candel, S.; Renshaw, S.A.; Mulero, V.; Calado, A. Cxcl8 (IL-8) mediates neutrophil recruitment and behavior in the zebrafish inflammatory response. J. Immunol. 2013, 190, 4349-4359. [CrossRef] [PubMed]

63. Benard, E.L.; Rougeot, J.; Racz, P.I.; Spaink, H.P.; Meijer, A.H. Transcriptomic Approaches in the Zebrafish Model for TuberculosisInsights Into Host- and Pathogen-specific Determinants of the Innate Immune Response. Adv. Genet. 2016, 95, 217-251. [PubMed]

64. Koller, A.; Brunner, S.M.; Bianchini, R.; Ramspacher, A.; Emberger, M.; Locker, F.; Schlager, S.; Kofler, B. Galanin is a potent modulator of cytokine and chemokine expression in human macrophages. Sci Rep. 2019, 9, 7237. [CrossRef]

65. Locker, F.; Lang, A.A.; Koller, A.; Lang, R.; Bianchini, R.; Kofler, B. Galanin modulates human and murine neutrophil activation in vitro. Acta Physiol. 2015, 213, 595-602. [CrossRef]

66. Schindler, C.W.; Darnell, J.E. Transcriptional responses to polypeptide ligands: The JAK-STAT pathway. Annu. Rev. Biochem. 1995, 64, 621-651. [CrossRef] [PubMed] 
67. Yamashita, S.; Miyagi, C.; Carmany-Rampey, A.; Shimizu, T.; Fujii, R.; Schier, A.F.; Hirano, T. STAT3 controls cell movements during zebrafish gastrulation. Dev. Cell 2002, 2, 363-375. [CrossRef]

68. Naylor, M.J.; Oakes, S.R.; Gardiner-Garden, M.; Harris, J.; Blazek, K.; Ho, T.W.; Li, F.C.; Wynick, D.; Walker, A.M.; Ormandy, C.J. Transcriptional Changes Underlying the Secretory Activation Phase of Mammary Gland Development. Mol. Endocrinol. 2005, 19, 1868-1883. [CrossRef]

69. Tiwari, B.M.; Kannan, N.; Vemu, L.; Raghunand, T.R. The Mycobacterium tuberculosis PE proteins Rv0285 and Rv1386 modulate innate immunity and mediate bacillary survival in macrophages. PLoS ONE 2012, 12, e51686. [CrossRef] [PubMed] 